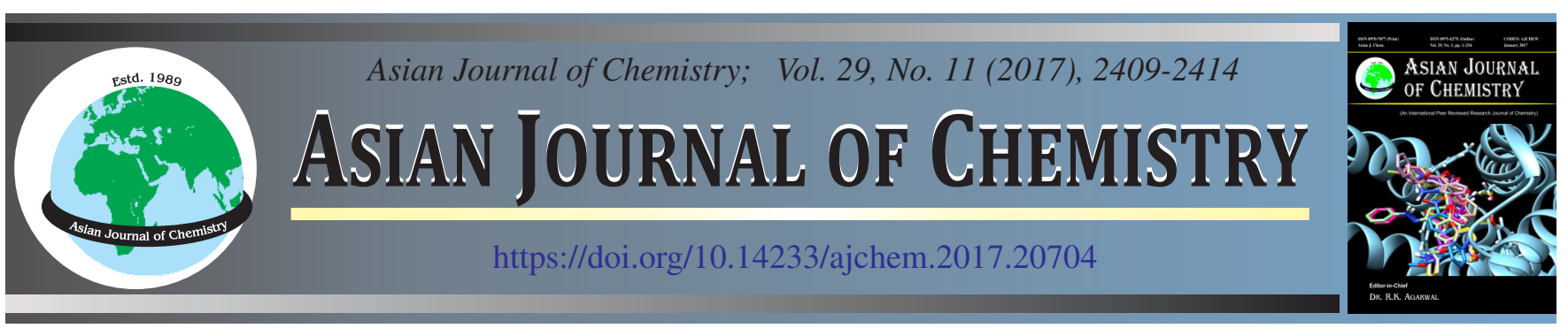

\title{
Green Synthesis of Silver Nanoparticles by Mint Leaves: A Suitable Catalyst for Oxidation of Metronidazole
}

\author{
Savita Pataila, Ajaya Kumar Singh*, Bhawana Jain and Gautam Sheel Thool
}

Department of Chemistry, Government V.Y.T. PG Autonomous College, Durg-491 001, India

*Corresponding author: E-mail: ajayaksingh_au@yahoo.co.in

Received: 12 April 2017;

Accepted: 15 July 2017;

Published online: 29 September 2017;

AJC-18561 of silver nanoparticles via an eco-friendly route is an active area of research because of its unique properties. Present work deals synesis of silver nanoparticles using mint leaves and its catalytic behaviour was explored for the oxidation of metronidazole (MTZ) by hexacyanoferrate (HCF) as an oxidant. Firstly, synthesized nanoparticles were characterized by UV-visible, scanning electron microscopy and Fourier transform infrared analysis. The degradation of metronidazole by hexacyanoferrate was studied spectrophometrically, both in the absence and presence of silver nanoparticles catalyst in basic medium under pseudo first order condition. It was observed that the silver nanoparticles as catalyst significantly increases the reaction rate and overall thermodynamic activation parameters were also calculated.

Keywords: Nanosilver catalyst, Oxidation, Metronidazole, Hexacyanoferrate.

ᄂ $-\ldots-\ldots-\ldots-\ldots-\ldots-\ldots-\ldots-\ldots-\ldots-\ldots-\ldots$

\section{INTRODUCTION}

Nanoparticles have great applications in various field i.e. environment, health, food, biomedical sciences, chemical industries, electronics, etc. [1-3]. One of the potential applications of nanoscience is to develop catalyst in nanosize which can provide high surface area, new catalytic properties and enhancement in the rate of reaction by several folds. Evaluating the catalytic performance and the reaction kinetics are major issues when new catalysts are synthesized, characterized and introduced [4]. Shape, size and distribution of the nanoparticles can control by adjusting the reaction conditions such as stabilizer, employing method, etc. Preparation of silver nanoparticles is an important area of research because of its idiosyncratic properties and application i.e. antimicrobial, biosensor material, cryogenic super conducting material, cosmetic product, etc. It is also used for the treatment of ulcer, dermatitis, etc. [5]. Silver nano catalyst is one of the most investigated catalysts owing to its distinct reactivity, selectivity, stability and recyclability in catalytic processes, it also prevents the growth of microbial pathogens and have anti-inflammatory, antiviral effect [6].

Large scale synthesis of silver nanoparticles can be achievable by chemical and physical methods, such as laser ablation, lithography, photochemical reduction $[7,8]$, etc. which remain high cost and occasionally involve the use of toxic chemicals that cause contamination on the surface of the silver nanoparticles and leads to adverse effects. Therefore, there is an urgent need to develop environmentally benign synthetic route that doesn't involve hazardous chemicals in the synthesis protocols. The biosynthesis of silver nanoparticles has become significant in the present scenario. A number of plants i.e. Cinnamomum zeylanicum, Cacumen platycladi extract, Pinus eldarica bark extract, have been reported to synthesize silver nanoparticles [9-11]. In present work, our synthetic strategy involves the use of mint leaves extract to synthesize nanosilver catalyst.

Daughton and Ternes [12] studied the presence of pharmaceutical waste in the environment . In recent years, metronidazole is being widely used because of its pharmaceutical significance as well as its veterinary use. It is an antiprotozoal drug of nitroimidazole derivative having activity against anaerobic bacteria and protozoans [13-15]. This compound is highly hazardous, if exposed in the environment owing to its carcinogenic and mutagenic nature and found as a persistent toxic waste and is frequently used for the protozoal infection [16-18]. Protozoal infection occurs throughout the world and are main cause of morbidity and mortality in South East Asia and Africa. Metronidazole, tinidazole, nifuratel and ronidazole are some miscellaneous antiprotozoal drug. These drugs causes nausea, vomiting, furred tongue and its very toxic to pregnant woman. Among these drugs for the present work we selected metronidazole, which is highly soluble in water, low biodegradable and easily get accumulated, resulting adverse effects to human and aquatic 
environment $[19,20]$. The detection limit for metronidazole in environment is $10-50 \mu \mathrm{g} / \mathrm{mL}$ [21]. Hence, it is important to develop a low cost, environmentally benign way to degrade metronidazole from aquatic system.

Hexacyanoferrate(III)/Hexacyanoferrate(II) is one electron oxidant with redox potential $+0.36 \mathrm{~V}$ [22], it is used as an oxidant for oxidation of variety of organic and inorganic compound in both basic and acidic medium [23,24]. The mechanism of such reaction involves the formation of outer sphere precursor complex between $\left[\mathrm{Fe}(\mathrm{CN})_{6}\right]^{3-}$ and substrate $[25,26]$, it is an electron abstracting reagent and oxidation mainly occur through direct charge transfer process $[27,28]$. Still, there is no report available on the oxidation of metronidazole by hexacyanoferrate in the absence and presence of nanosilver catalyst in alkaline medium. It is area of great interest to understand the redox chemistry of Hexacyanoferrate(III).

In this study, we have acquired the green synthesis of silver nanoparticles using mint leaves extract, which was further confirmed by UV-visible, FESEM and FTIR.

\section{EXPERIMENTAL}

Metronidazole was purchased from Sigma Aldrich (Mumbai), which later used without further purification for the preparation of stock solution, sodium hydroxide (E. Merck), $\mathrm{AgNO}_{3}$, hexacyanoferrate were obtained from Merck. Silver nitrate used as silver source to prepare nanosilver catalyst and double distilled water was used for the preparation of solution.

Preparation of the mint leaves extract (MLE): Mint leaves extract was prepared by fresh leaves of mint, $25 \mathrm{~g}$ of leave were thoroughly washed thrice in double distilled water for $15 \mathrm{~min}$, dried, cut into fine pieces and were boiled in a 500 $\mathrm{mL}$ conical flask with $100 \mathrm{~mL}$ of double distilled water for 30 min and were filtered. The filtrate acted as both reducing and stabilizing agent to prepare nanosilver catalyst. Silver nitrate solution (without mint leaves extract) neither developed the reddish brown colour nor displayed the characteristic peaks of silver nanoparticles (Fig. 1), indicated the mint leaves extract only reducing $\mathrm{Ag}^{+}$to $\mathrm{Ag}^{\circ}$, therefore it acted as reducing agent. The polyphenol and flavonoid content in the mint leaves extract were estimated using standard methods reported elsewhere in the literature [29]. In brief, $5 \mathrm{~mL}$ of dilute ammonia solution is added to the mint leaves extract followed by addition of conc. sulphuric acid, turned a yellow coloured solution indicated the presence of flavonoids in mint leave extract.

Synthesis of nanosilver catalyst: Silver nitrate solution was prepared in double distilled water. $50 \mathrm{~mL}$ mint leaves extract was added to a vigorously stirred $25 \mathrm{~mL}$ aqueous solution of $\mathrm{AgNO}_{3}\left(1 \times 10^{-2} \mathrm{M}\right)$ and stirring continued for $1 \mathrm{~min}$. Appearance of reddish brown colour of solution indicated the formation of silver nanoparticles. The formation of $\mathrm{Ag}^{\circ}$ was monitored by recording UV-visible spectrum of the above solution at different time intervals after diluting a small aliquot of $1 \mathrm{~mL}$ of the sample with $4 \mathrm{~mL}$ double distilled water. We observed that an absorption peak developed in the wavelength range of 370 to 600 $\mathrm{nm}$, centered at $435 \mathrm{~nm}$ confirmed the formation of silver nanoparticles. The intensity of the peak increased with time.

Characterization techniques: The UV-visible spectra were recorded using Varian, CARY 50 BIO UV-visible spectro- photometer with samples in quartz cuvette. The colloidal nanosilver catalyst solution was centrifuged at $12000 \mathrm{rpm}$ for $15 \mathrm{~min}$ at $0{ }^{\circ} \mathrm{C}$, supernatant was decanted off and finally nanosilver catalyst were collected. The obtained nanosilver catalyst was washed thrice with double distilled water followed by ethanol. The morphology of as-synthesized nanosilver catalyst was studied by VEGA II LSU SEM and FTIR spectra was recorded using Thermo Nicolet Nexus 670 spectrometer with $4 \mathrm{~cm}^{-1}$ resolutions.

The detailed kinetic study for the oxidation of metronidazole by alkaline hexacyanoferrate in the absence and presence of nanosilver catalyst were carried out under pseudo first order condition where $[\mathrm{MTZ}]>\left[\mathrm{Fe}(\mathrm{CN})_{6}\right]^{3-}$. The reaction was carried out by mixing the appropriate quantity of thermostated solutions of metronidazole and hexacyanoferrate which also contained fixed quantity of $\mathrm{NaOH}$ to maintain the alkalinity on the reaction mixture.

\section{RESULTS AND DISCUSSION}

\section{Characterization of nanosilver catalyst}

UV-visible spectral: UV-visible spectroscopy is an important tool to determine the formation and stability of nanosilver catalyst. One of the most characteristics of silver nanoparticles is the sharp surface plasmon resonance (SPR) band appeared in the region of 350-600 $\mathrm{nm}$ [30]. In present study, the spectrum of as-synthesized nanosilver catalyst consists of single SPR band centered at $435 \mathrm{~nm}$ in the visible region. The shape of the SPR band suggests about the size distribution of silver nanoparticles [31]. Different size distribution and non-uniform shape usually leads to broaden the SPR band. Silver nitrate solution (without mint leaves extract) neither developed the reddish brown colour nor displayed the characteristic peaks of metallic nanosilver (Fig. 1). This result eliminated the possibility of the abiotic reduction of silver nitrate under the reaction conditions. It is observed that the SPR bands were broadened with an absorption tail in the longer wavelengths, which may be due to the different size and shape distribution of the nanoparticles (also verified by SEM analysis).

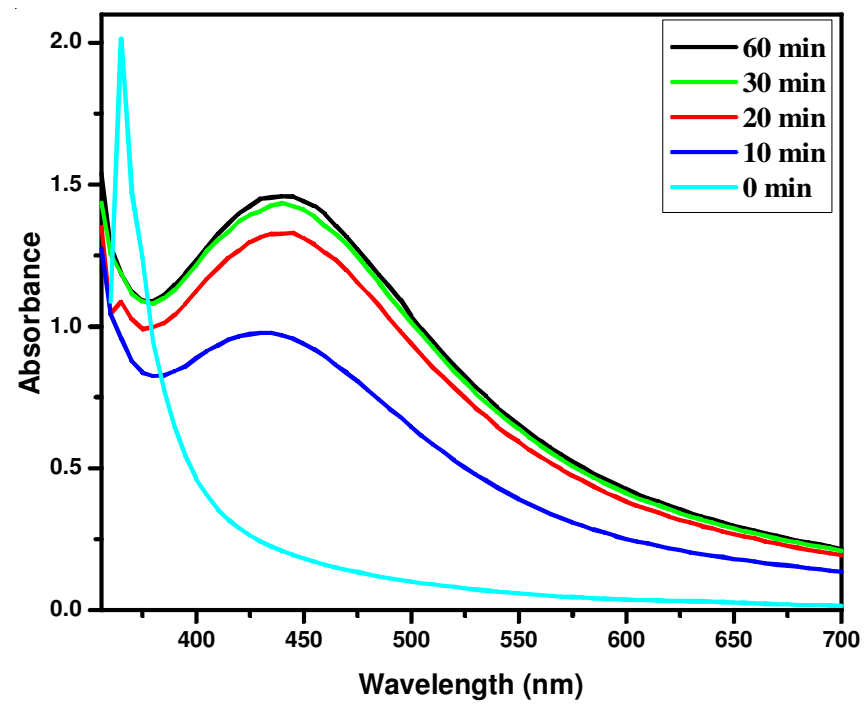

Fig. 1. UV-visible absorption spectra of colloidal nanosilver catalyst solution recorded at different time intervals. At time zero, no mint leaves extract was added in the silver nitrate solution 
Morphological study: Fig. 2 showed the FE-scanning electron micrographs of the nanosilver catalyst at different magnifications. It is clearly observed that two different kinds of structures are existing i.e. nanocubes and microplates. The average size of the nanocubes and microplates are $\sim 777 \mathrm{~nm}$ and $\sim 2.8 \mu \mathrm{m}$, respectively.
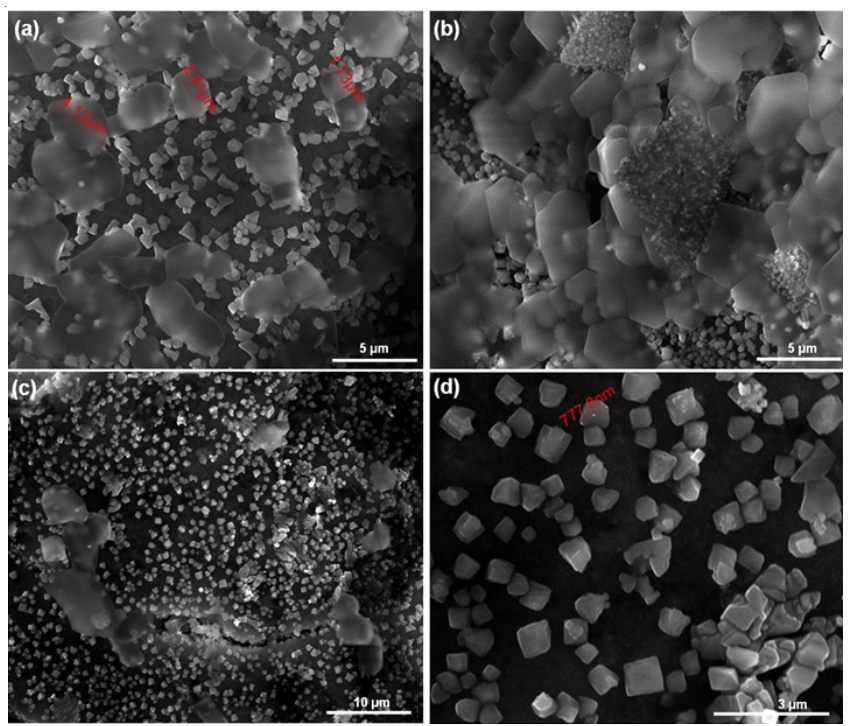

Fig. 2. FESEM images of as synthesized nanosilver catalyst at different magnifications

FTIR analysis: To investigate the organic moieties participating in the formation of nanosilver catalyst, FTIR analysis was carried out in the wave number range from 4000 to 400 $\mathrm{cm}^{-1}$ using $\mathrm{KBr}$ method at room temperature (Fig. 3). A series of infrared bands were observed in the spectrum. The broad peak centred at $3421.61 \mathrm{~cm}^{-1}$ corresponds to $\mathrm{O}-\mathrm{H}$ stretching vibration frequency, indicated the presence of hydroxyl group which could be adsorbed water on the surface of the nanosilver catalyst. The $\mathrm{C}-\mathrm{H}$ stretching frequency arises at around $2924.15 \mathrm{~cm}^{-1}$ and depicts the presence of an alkyl group. The bands appeared at different vibrational frequencies such as $1625.11 \mathrm{~cm}^{-1}, 1380.42 \mathrm{~cm}^{-1}$ and $1021.84 \mathrm{~cm}^{-1}$ corresponding to $\mathrm{C}=\mathrm{C}$ (aromatic ring), aromatic amines and aliphatic amines respectively, are strongly supported the capping and reducing behaviour of mint leaves extract.

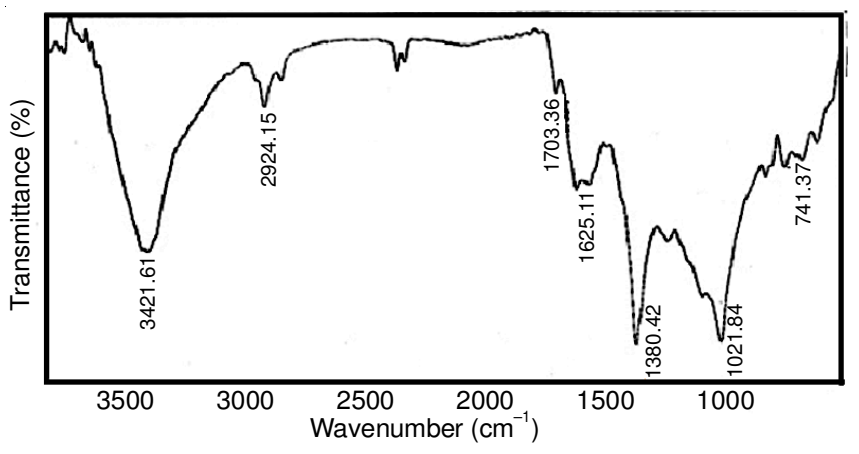

Fig. 3. FTIR spectrum of as synthesized nanosilver catalyst

Kinetic study for oxidation of metronidazole by hexacyanoferrate in the presence and absence of nanosilver catalyst: The progress of reaction was followed spectrophoto- metrically by monitoring absorbance of unreacted hexacyanoferrate in the reaction mixture at the $\lambda_{\max }$ i.e. $410 \mathrm{~nm}$, as a function of time (Figs. 4 and 5). The applicability of Beer's law was verified at $410 \mathrm{~nm}$ and it was verified that no other species present in the reaction mixture interfere at this wavelength. The pseudo first order rate constants $\mathrm{k}_{\mathrm{obs}}$ were calculated from the plots of log (absorbance) $v s$. time for the completion of $85 \%$ of reaction with the varying concentration of oxidant, reductant and catalyst. The rate constants were reproducible within $\pm 5 \%$ and are average of at three independent kinetic runs.

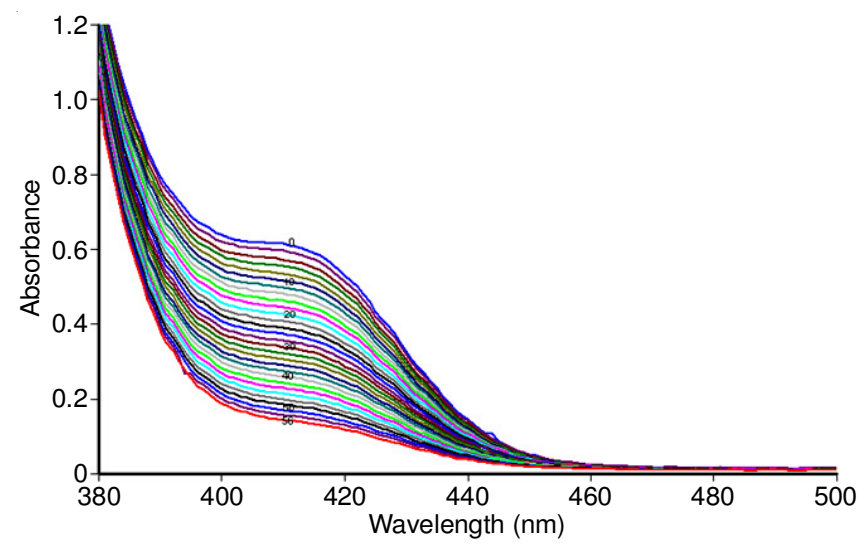

Fig. 4. Spectral changes during the oxidation of metronidazole by $\left[\mathrm{K}_{3} \mathrm{Fe}(\mathrm{CN})_{6}\right]$ in alkaline medium at $301 \mathrm{~K}:\left[\mathrm{K}_{3} \mathrm{Fe}(\mathrm{CN})_{6}\right]=6 \times 10^{-4} \mathrm{M}$, $[\mathrm{MTZ}]=6 \times 10^{-3} \mathrm{M},\left[\mathrm{OH}^{-}\right]=1.5 \times 10^{-2} \mathrm{M}$, time interval $=2 \mathrm{~min}$, upto $112 \mathrm{~min}$

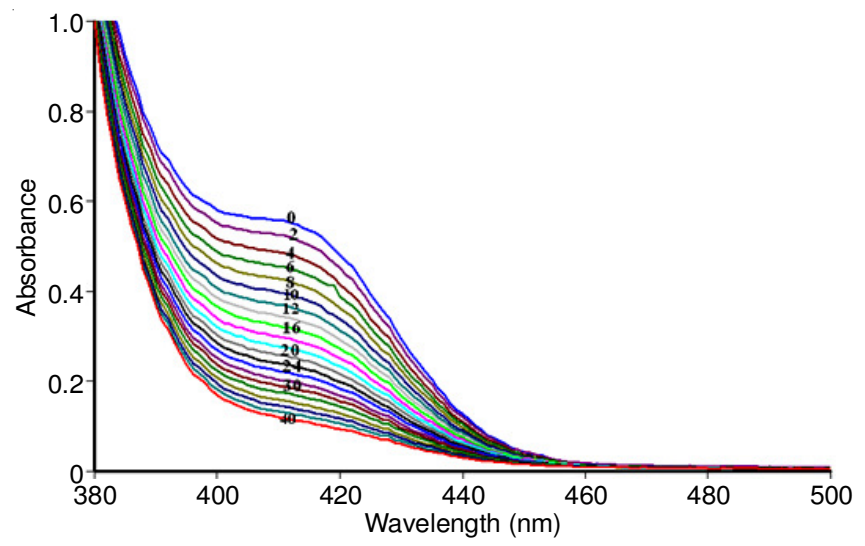

Fig. 5. Spectral changes during the oxidation of metronidazole by $\left[\mathrm{K}_{3} \mathrm{Fe}(\mathrm{CN})_{6}\right]$ in alkaline medium at $301 \mathrm{~K}:\left[\mathrm{K}_{3} \mathrm{Fe}(\mathrm{CN})_{6}\right]=6 \times 10^{-4}$ $\mathrm{M},[\mathrm{MTZ}]=6 \times 10^{-3} \mathrm{M},\left[\mathrm{OH}^{-}\right]=1.5 \times 10^{-2} \mathrm{M},\left[\mathrm{Ag}^{\circ}\right]=4 \times 10^{-6} \mathrm{M}$, time interval $=2 \mathrm{~min}$, upto $40 \mathrm{~min}$

Reaction order: Oxidation of metronidazole by alkaline hexacyanoferrate $\left[\mathrm{Fe}(\mathrm{CN})_{6}\right]^{3-}$ studied separately for both uncatalyzed and nanosilver catalyzed reactions under pseudofirst order reaction condition. It was observed that the rate of reaction increased for nanosilver catalyzed reaction. The rate constant was determined for each experimental set in order to know the dependence of reaction rate on each reactant. The reaction orders were determined from the slope of the plot between $\log \mathrm{k}_{\mathrm{obs}} v s$. $\log$ [reactant].

A continuous decrease in rate $\left(\mathrm{k}_{\mathrm{obs}}\right)$ with the increase in oxidant concentration $\left(1 \times 10^{-4}\right.$ to $\left.10 \times 10^{-4} \mathrm{M}\right)$ for both uncatalyzed and nanosilver catalyzed reaction were observed (Table-1). 
The experimental results showed that rate of the reaction increased for both uncatalyzed and catalyzed reaction with increase in metronidazole concentration in the range of $(2 \times$ $10^{-3}$ to $\left.20 \times 10^{-3} \mathrm{M}\right)$ at constant $\left[\mathrm{Fe}(\mathrm{CN})_{6}\right]^{3-},\left[\mathrm{OH}^{-}\right]$and $\left[\mathrm{Ag}^{\circ}\right]$. Plot of $\log \mathrm{k}$ vs. $\log$ [MTZ] was linear, indicated first order reaction with respect to metronidazole (Fig. 6, Table-1).

\begin{tabular}{|c|c|c|c|c|}
\hline \multicolumn{5}{|c|}{$\begin{array}{c}\text { TABLE-1 } \\
\text { EFFECT OF VARIATION OF }\left[\mathrm{Fe}(\mathrm{CN})_{6}\right]^{3-},[\mathrm{MTZ}],\left[\mathrm{OH}^{-}\right] \\
\text {ON THE OXIDATION OF METRONIDAZOLE BY } \\
\text { HEXACYANOFERRATE IN ALKALINE MEDIUM } \\
\text { FOR BOTH UNCATALYZED AND NANOSILVER } \\
\text { CATALYZED REACTION AT } 301 \mathrm{~K}\end{array}$} \\
\hline $\begin{array}{c}10^{4} \\
{\left[\mathrm{Fe}(\mathrm{CN})_{6}\right]^{3-}} \\
\quad(\mathrm{M})\end{array}$ & $\begin{array}{c}10^{3}[\mathrm{MTZ}] \\
\text { (M) }\end{array}$ & $\begin{array}{c}10^{2}[\mathrm{OH}] \\
(\mathrm{M})\end{array}$ & $\begin{array}{l}10^{4} \mathrm{k}_{\mathrm{obs}}\left(\mathrm{s}^{-1}\right) \\
\text { Uncatalyzed }\end{array}$ & $\begin{array}{c}10^{4} \mathrm{k}_{\text {obs }}\left(\mathrm{s}^{-1}\right) \\
\text { (Nanosilve } \\
\text { catalyzed) } \\
\mathrm{Ag}^{\circ}\end{array}$ \\
\hline 1.0 & 6.0 & 1.5 & 7.36 & 14.13 \\
\hline 2.0 & 6.0 & 1.5 & 5.11 & 11.98 \\
\hline 4.0 & 6.0 & 1.5 & 4.42 & 8.15 \\
\hline 5.0 & 6.0 & 1.5 & 3.67 & 7.53 \\
\hline 6.0 & 6.0 & 1.5 & 2.54 & 6.07 \\
\hline 8.0 & 6.0 & 1.5 & 2.39 & 5.27 \\
\hline 10.0 & 6.0 & 1.5 & 2.29 & 4.78 \\
\hline 6.0 & 2.0 & 1.5 & 0.85 & 2.64 \\
\hline 6.0 & 4.0 & 1.5 & 1.65 & 4.09 \\
\hline 6.0 & 6.0 & 1.5 & 2.14 & 6.01 \\
\hline 6.0 & 8.0 & 1.5 & 3.71 & 8.06 \\
\hline 6.0 & 10.0 & 1.5 & 4.91 & 10.9 \\
\hline 6.0 & 12.0 & 1.5 & 6.17 & 13.81 \\
\hline 6.0 & 14.0 & 1.5 & 7.57 & 15.73 \\
\hline 6.0 & 16.0 & 1.5 & 8.38 & 16.88 \\
\hline 6.0 & 20.0 & 1.5 & 10.13 & 20.03 \\
\hline 6.0 & 6.0 & 0.5 & 0.70 & 1.54 \\
\hline 6.0 & 6.0 & 1.0 & 1.41 & 3.73 \\
\hline 6.0 & 6.0 & 1.5 & 2.12 & 5.90 \\
\hline 6.0 & 6.0 & 2.0 & 2.80 & 8.59 \\
\hline 6.0 & 6.0 & 2.5 & 3.50 & 10.56 \\
\hline 6.0 & 6.0 & 3.0 & 4.20 & 11.62 \\
\hline 6.0 & 6.0 & 4.0 & 5.60 & 12.67 \\
\hline 6.0 & 6.0 & 5.0 & 7.01 & 14.77 \\
\hline
\end{tabular}

$\left[\mathrm{Ag}^{\circ}\right]=4 \times 10^{-6} \mathrm{M}$ for catalyzed reaction

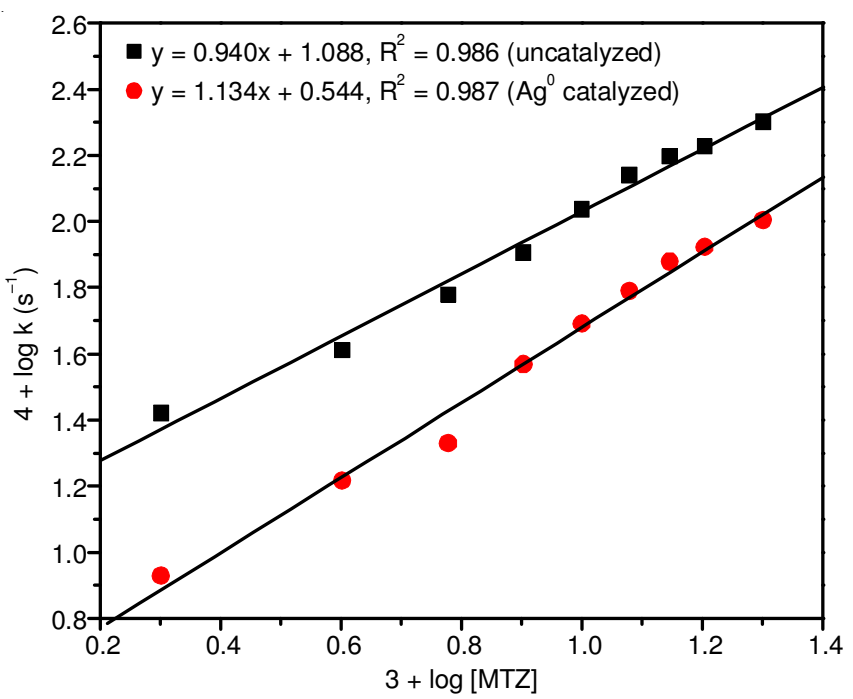

Fig. 6. Plot of $3+\log [\mathrm{MTZ}]$ vs. $4+\log \mathrm{k}_{\mathrm{ob}}$; Reaction condition: uncatalyzed $=\left[\mathrm{K}_{3} \mathrm{Fe}(\mathrm{CN})_{6}\right]=6 \times 10^{-4} \mathrm{M},\left[\mathrm{OH}^{-}\right]=1.5 \times 10^{-2} \mathrm{M},[\mathrm{MTZ}] \times 10^{-3} \mathrm{M}$ $=2.0,4.0,6.0,8.0,10.0,12.0,14.0,16.0,20.0 ;$ catalyzed $=$ $\left[\mathrm{K}_{3} \mathrm{Fe}(\mathrm{CN})_{6}\right]=6 \times 10^{-4} \mathrm{M},\left[\mathrm{OH}^{-}\right]=1.5 \times 10^{-2} \mathrm{M},\left[\mathrm{Ag}^{\circ}\right]=4.0 \times 10^{-6}$ $\mathrm{M},[\mathrm{MTZ}] \times 10^{-3} \mathrm{M}=2.0,4.0,6.0,8.0,10.0,12.0,14.0,16.0,20.0$
To study the effect of $\left[\mathrm{OH}^{-}\right]$on the rate of reaction, $\mathrm{NaOH}$ concentration varied in the range of $0.5 \times 10^{-2}$ to $5.0 \times 10^{-2} \mathrm{M}$ by keeping other reactants constants i.e. $\left[\mathrm{Fe}(\mathrm{CN})_{6}\right]^{3-}$, [MTZ] and $\left[\mathrm{Ag}^{\circ}\right]$ at $301 \mathrm{~K}$. The result elucidated that the rate of reaction increased with $\left[\mathrm{OH}^{-}\right]$. Plot of $\log \mathrm{k}$ vs. $\log \left[\mathrm{OH}^{-}\right]$was linear with fractional value of slope indicated fractional order of reaction with respect to medium (Fig. 7).

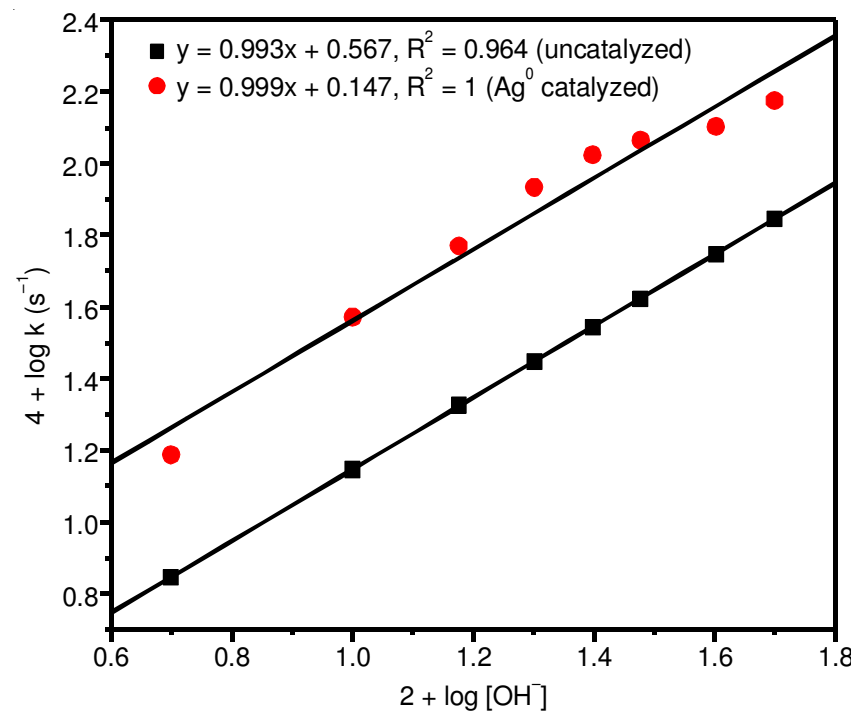

Fig. 7. Plot of $2+\log \left[\mathrm{OH}^{-}\right]$vs. $4+\log \mathrm{k}_{\mathrm{obs}}$; Reaction condition: uncatalyzed $=\left[\mathrm{K}_{3} \mathrm{Fe}(\mathrm{CN})_{6}\right]=6 \times 10^{-4} \mathrm{M},[\mathrm{MTZ}]=6 \times 10^{-3} \mathrm{M},\left[\mathrm{OH}^{-}\right] 10^{-2} \mathrm{M}=$ $0.5,1.0,1.5,2.0,2.5,3.0,4.0,5.0 ;$ Catalyzed $=\left[\mathrm{K}_{3} \mathrm{Fe}(\mathrm{CN})_{6}\right]=6 \times$ $10^{-4} \mathrm{M},[\mathrm{MTZ}]=6 \times 10^{-3} \mathrm{M},\left[\mathrm{Ag}^{\circ}\right]=4 \times 10^{-6} \mathrm{M}\left[\mathrm{OH}^{-}\right] 10^{-2} \mathrm{M}=0.5$, $1.0,1.5,2.0,2.5,3.0,4.0,5.0$

To find the effect of silver nanocatalyst, $\left[\mathrm{Ag}^{\circ}\right]$ varied in the range of $2.0 \times 10^{-6}$ to $20.0 \times 10^{-6} \mathrm{M}$ at while concentration of other reactants was constant at $301 \mathrm{~K}$. The result showed that rate of reaction increased with increase in $\left[\mathrm{Ag}^{\circ}\right]$. Plot of $\log \mathrm{k}$ vs. $\log \left[\mathrm{Ag}^{\circ}\right]$ was linear with fractional value of slope $(0.4)$, indicated that the reaction followed fractional order with respect to nanosilver catalyst (Fig. 8 and Table-2).

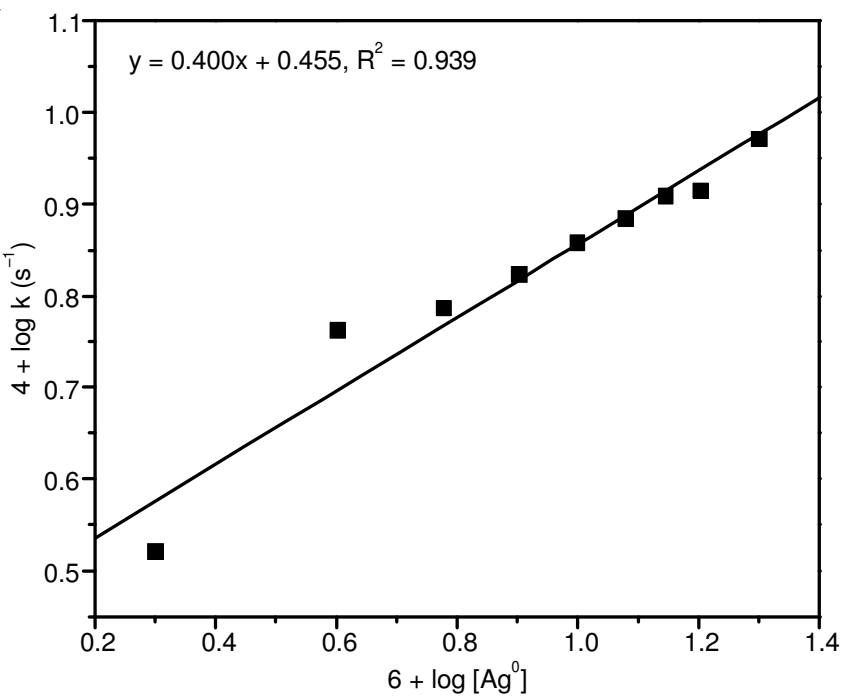

Fig. 8. Plot of $6+\log \left[\mathrm{Ag}^{\circ}\right]$ vs. $4+\log \mathrm{k}_{\mathrm{obs}}$; Reaction conditions: $\left[\mathrm{K}_{3} \mathrm{Fe}(\mathrm{CN})_{6}\right]=6 \times 10^{-4} \mathrm{M},[\mathrm{MTZ}]=6 \times 10^{-3} \mathrm{M},\left[\mathrm{OH}^{-}\right]=1.5 \times 10^{-2}$ $\mathrm{M},\left[\mathrm{Ag}^{\circ}\right] 10^{-6} \mathrm{M}=2.0,4.0,6.0,8.0,10.0,12.0,14.0,16.0,20.0$ 


\begin{tabular}{cc}
\hline \multicolumn{2}{c}{ TABLE-2 } \\
EFFECT OF NANOSILVER CATALYST IN THE OXIDATION \\
OF METRONIDAZOLE BY HEXACYANOFERRATE \\
\hline $\mathrm{Ag}^{\circ}$ [Catalyst] $10^{6}$ & $10^{4} \mathrm{k}_{\text {obs }}\left(\mathrm{s}^{-1}\right)$ \\
\hline 2.0 & 3.32 \\
4.0 & 5.80 \\
6.0 & 6.12 \\
8.0 & 6.66 \\
10.0 & 7.22 \\
12.0 & 7.66 \\
14.0 & 8.11 \\
16.0 & 8.22 \\
20.0 & 9.36 \\
\hline
\end{tabular}

The concentration of hexacyanoferrate(II) varied by keeping all the reaction condition constant. Constant value in the rate clearly showed that change in the concentration of hexacyanoferrate does not affect the oxidation of metronidazole in the absence or presence of nanocatalyst. Variation of ionic strength of the medium by the addition of variable amount of $\mathrm{KNO}_{3}$ $(0.02$ to $0.1 \mathrm{M})$ had no effect on the rate of reaction. The effect of dielectric permittivity (D) of the medium on the reaction rate was studied by varying the percentage of acetonitrile (0$30 \%$ ) in the reacting system. The results revealed that the rate of reaction decreased with increase in percentage of solvent. A plot of $\log \mathrm{k}_{\mathrm{obs}} v s$. 1/D exhibit straight line with negative slope. The permittivity (D) for $\mathrm{CH}_{3} \mathrm{CN}-\mathrm{H}_{2} \mathrm{O}$ mixtures were calculated with the help of the following equation, $\mathrm{D}=\mathrm{D}_{\mathrm{W}} \mathrm{V}_{\mathrm{W}}+\mathrm{D}_{\mathrm{A}} \mathrm{V}_{\mathrm{A}}$, where $V_{W}$ and $V_{A}$ are the volume fractions of water and acetonitrile whereas $D_{W}$ and $D_{A}$ are the dielectric permittivity of pure water and acetonitrile, respectively.

Effect of temperature: The reaction was studied at different temperatures (298-318 K) keeping other experimental conditions constant. From Arrhenius plot of $\log \mathrm{k} v s .1 / \mathrm{T}$ the values of thermodynamic parameters were calculated for both uncatalyzed and nanosilver catalyzed reactions These values confirmed that formation of activation complex was easier in the case of nanosilver catalyzed reaction (Fig. 9 and Table-3).

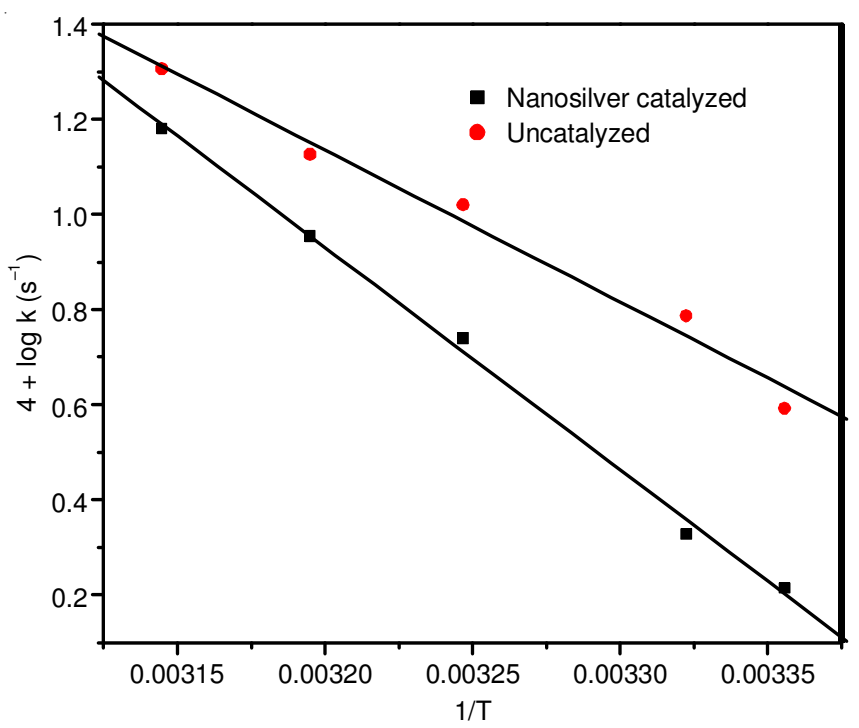

Fig. 9. Plot of $1 / \mathrm{T}$ vs. $4+\log \mathrm{k}_{\mathrm{obs}}$; Reaction Conditions: Uncatalyzed $=$ $\left[\mathrm{K}_{3} \mathrm{Fe}(\mathrm{CN})_{6}\right]=6 \times 10^{-4} \mathrm{M},[\mathrm{MTZ}]=6 \times 10^{-3} \mathrm{M},\left[\mathrm{OH}^{-}\right]=1.5 \times 10^{-2}$ $\mathrm{M}$, Catalyzed $=\left[\mathrm{K}_{3} \mathrm{Fe}(\mathrm{CN})_{6}\right]=6 \times 10^{-4} \mathrm{M},[\mathrm{MTZ}]=6 \times 10^{-3} \mathrm{M}$, $\left[\mathrm{OH}^{-}\right]=1.5 \times 10^{-2} \mathrm{M}\left[\mathrm{Ag}^{\circ}\right]=4 \times 10^{-6} \mathrm{M}$

\begin{tabular}{|c|c|c|}
\hline \multicolumn{3}{|c|}{$\begin{array}{c}\text { TABLE-3 } \\
\text { EFFECT OF VARYING TEMPERATURE ON THE } \\
\text { REACTION RATE AND ACTIVATION PARAMETERS } \\
\text { FOR THE OXIDATION OF METRONIDAZOLE }\end{array}$} \\
\hline Temperature (K) & $\begin{array}{l}10^{4} \mathrm{k}_{\text {obs }}\left(\mathrm{s}^{-1}\right) \\
\text { Uncatalyzed }\end{array}$ & $10^{4} \mathrm{k}_{\text {obs }}\left(\mathrm{s}^{-1}\right) \mathrm{Ag}^{\circ}$ \\
\hline 298 & 1.64 & 3.91 \\
\hline 301 & 2.13 & 6.12 \\
\hline 308 & 5.50 & 10.48 \\
\hline 313 & 9.00 & 13.40 \\
\hline 318 & 15.17 & 20.24 \\
\hline $\mathrm{E}_{\mathrm{a}}\left(\mathrm{kJ} \mathrm{mol}^{-1}\right)$ & 89.59 & 61.12 \\
\hline$\Delta \mathrm{H}^{\#}\left(\mathrm{~kJ} \mathrm{~mol}^{-1}\right)$ & 87.09 & 58.63 \\
\hline$\Delta \mathrm{S}^{\#}\left(\mathrm{~J} \mathrm{~K} \mathrm{~mol}^{-1}\right)$ & 17.65 & 103.53 \\
\hline$\Delta \mathrm{G}^{\#}\left(\mathrm{~kJ} \mathrm{~mol}^{-1}\right)$ & 81.77 & 27.46 \\
\hline $\log \mathrm{Pz}^{\mathrm{c}}$ & -3.671 & -3.213 \\
\hline $\begin{array}{l}\text { Reaction condition } \\
{\left[\mathrm{OH}^{-}\right]=1.5 \times 10^{-2}}\end{array}$ & N) $\left.)_{6}\right]=6 \times$ & {$[\mathrm{TZ}]=6 \times 10^{-3} \mathrm{I}$} \\
\hline
\end{tabular}

Stoichiometry and product analysis: To determine the oxidation products, different sets of reaction mixture containing different ratio of hexacyanoferrate to metronidazole with a certain amount of $\mathrm{OH}^{-}$in the reaction mixture and kept in thermostatic water bath at $303 \mathrm{~K}$ for $72 \mathrm{~h}$. The unreacted amount of hexacyanoferrate was assayed spectrophotometrically at the wavelength of $410 \mathrm{~nm}$. The result indicated that one mole of metronidazole was consumed by one moles of hexacyanoferrate for both the reactions. The main reaction product of oxidation of metronidazole was supposed to be 2-methyl5-nitro-1-imidazole ethanal as reported in the literature. The reaction products were extracted with ether. The aldehyde was detected by usual spot tests and also by 2,4-dinitrophenyl hydrazine derivative [32].

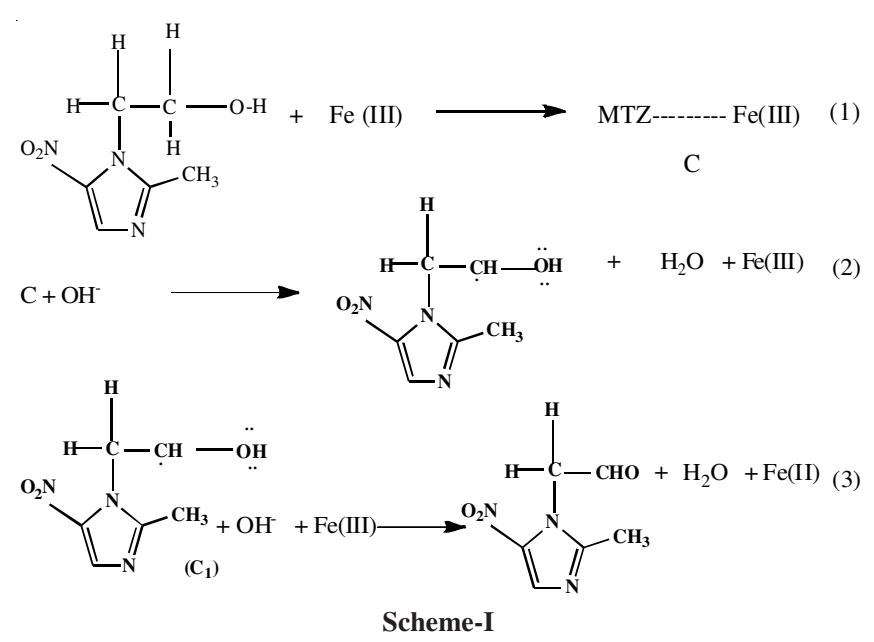

Spectral evidence for the complex formation: Spectral evidence for the complex formation between oxidant and substrate was found from UV-visible spectra of metronidazole, $\left[\mathrm{Fe}(\mathrm{CN})_{6}\right]^{3-},\left[\mathrm{OH}^{-}\right],\left[\mathrm{Ag}^{\circ}\right]$ and a mixture of metronidazole and $\left[\mathrm{Fe}(\mathrm{CN})_{6}\right]^{3-}$ (Fig. 10). Absorption peaks appeared at $315 \mathrm{~nm}$ and $410 \mathrm{~nm}$ for metronidazole and $\left[\mathrm{Fe}(\mathrm{CN})_{6}\right]^{3-}$, respectively. Hypsochromic shifts from 315 to $290 \mathrm{~nm}$ of metronidazole suggested that there was complex formation between metronidazole and $\left[\mathrm{Fe}(\mathrm{CN})_{6}\right]^{3-}$. Spectral evidence showed that absorbance was increased with increase in [MTZ] which was result of complex formation between metronidazole and oxidant. 


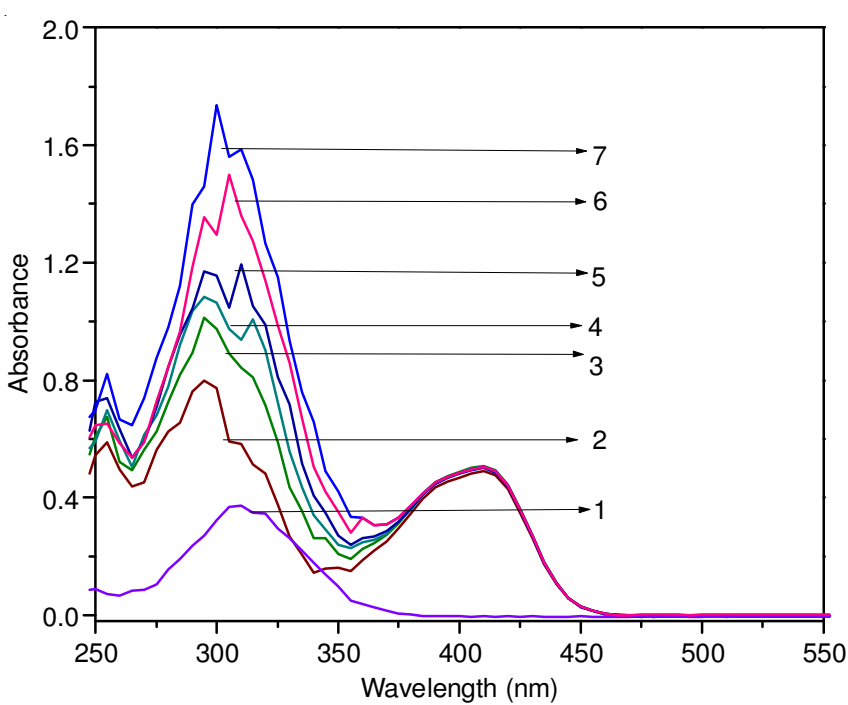

Fig. 10. Spectra of the solution [1-7] recorded at room temperature, solution conditions: 1 . $[\mathrm{MTZ}]=8.0 \times 10^{-5} \mathrm{M}, 2 .[\mathrm{HCF}]=8.0 \times 10^{-5} \mathrm{M}, 3$. $[\mathrm{MTZ}]=8.0 \times 10^{-5} \mathrm{M},[\mathrm{HCF}]=8.0 \times 10^{-5}, 4 .[\mathrm{MTZ}]=1.0 \times 10^{-4} \mathrm{M}$, $[\mathrm{HCF}]=8.0 \times 10^{-5}, 5 .[\mathrm{MTZ}]=1.5 \times 10^{-4} \mathrm{M},[\mathrm{HCF}]=8.0 \times 10^{-5}, 6$. $[\mathrm{MTZ}]=2.0 \times 10^{-4} \mathrm{M},[\mathrm{HCF}]=8.0 \times 10^{-5}, 7 .[\mathrm{MTZ}]=3.0 \times 10^{-4} \mathrm{M}$, $[\mathrm{HCF}]=8.0 \times 10^{-5}$

\section{Conclusion}

We have successfully synthesized and employed nanosilver catalyst for the degradation of metronidazole in a pseudo first order reaction condition. The oxidation of metronidazole became more facile in the presence of nanosilver catalyst. The oxidation product of metronidazole is found to be 2-methyl5-nitro-1-imidazole ethanal.

\section{ACKNOWLEDGEMENTS}

One of the authors, Savita Pataila is thankful to UGC, New Delhi for the award of Rajiv Gandhi National Fellowship.

\section{REFERENCES}

1. V.L. Colvin, M.C. Schlamp and A.P. Alivisatos, Nature, 370, 354 (1994); https://doi.org/10.1038/370354a0.

2. G. Schmid, Chem. Rev., 92, 1709 (1992); https://doi.org/10.1021/cr00016a002.

3. Y. Wang and N. Herron, J. Phys. Chem, 95, 525 (1991); https://doi.org/10.1021/j100155a009.

4. V. Joseph, C. Engelbrekt, J. Zhang, U. Gernert, J. Ulstrup and J. Kneipp, Angew. Chem. Int. Ed., 51, 7592 (2012); https://doi.org/10.1002/anie.201203526.

5. S. Iravani, H. Korbekandi, S.V. Mirmohammadi and B. Zolfaghari, Res. Pharma. Sci., 9, 385 (2014).

6. X.Y. Dong, Z.W. Gao, K.F. Yang, W.Q. Zhang and L.W. Xu, Catal. Sci. Technol., 5, 2554 (2015); https://doi.org/10.1039/C5CY00285K.

7. I.M. Chung, I. Park, K. Seung-Hyun, M. Thiruvengadam and G. Rajakumar, Nanoscale Res. Lett., 11, 40 (2016); https://doi.org/10.1186/s11671-016-1257-4.

8. Y. Park, Toxicol. Res., 30, 169 (2014); https://doi.org/10.5487/TR.2014.30.3.169.
9. S. Ahmed, M. Ahmad, B.L. Swami and S. Ikram, J. Adv. Res., 7, 17 (2016); https://doi.org/10.1016/j.jare.2015.02.007.

10. J. Huang, G. Zhan, B. Zheng, D. Sun, F. Lu, Y. Lin, H. Chen, Z. Zheng, Y. Zheng and Q. Li, Ind. Eng. Chem., 50, 9095 (2011); https://doi.org/10.1021/ie200858y.

11. M. Sathish Kumar, K. Sneha, S.W. Won, C.W. Cho, S. Kim and Y.S. Yun, Colloids Surf. B Biointerfaces, 73, 332 (2009); https://doi.org/10.1016/j.colsurfb.2009.06.005.

12. C.G. Daughton and T. Ternes, Environ. Health Perspect., 107(Suppl 6), 907 (1999); https://doi.org/10.1289/ehp.99107s6907.

13. K.N. Mohana and P.M. Ramdas Bhandarkar, J. Iran. Chem. Soc., 6, 277 (2009); https://doi.org/10.1007/BF03245835.

14. R.V. Puttaswamy, R.V. Jagadeesh and N.M.M. Gowda, Int. J. Chem. Kinet., 37, 700 (2005); https://doi.org/10.1002/kin.20118.

15. M.B. Johnson and M. Mehrvar, Ind. Eng. Chem. Res., 47, 6525 (2008); https://doi.org/10.1021/ie071637v.

16. M. Vertzoni, A. Carlsson, B. Abrahamsson, K. Goumas and C. Reppas, Int. J. Pharm., 413, 81 (2011); https://doi.org/10.1016/j.ijpharm.2011.04.028.

17. A. Bendesky, D. Menendez and P.O. Wegman, Mutat. Res., 511, 133 (2002); https://doi.org/10.1016/S1383-5742(02)00007-8.

18. Z. Fang, J. Chen, X. Qiu, X. Qiu, W. Cheng and L. Zhu, Desalination, 268, 60 (2011); https://doi.org/10.1016/j.desal.2010.09.051.

19. J. Rivera-Utrilla, G. Prados-Joya, M. Sánchez-Polo, M.A. Ferro-García and I. Bautista-Toledo, J. Hazard. Mater, 170, 298 (2009); https://doi.org/10.1016/j.jhazmat.2009.04.096.

20. M. Mohajerani, M. Mehrvar and F. Ein-Mozaffari, Ind. Eng. Chem. Res., 49, 5367 (2010); https://doi.org/10.1021/ie900906e.

21. C. Han, J. Chen, X. Wu, Y.W. Huang and Y. Zhao, Talanta, 128, 293 (2014); https://doi.org/10.1016/j.talanta.2014.04.083.

22. A.A.P. Khan, A.M. Asiri, A. Khan, N. Azum, M.A. Rub, M.M. Rahman, S.B. Khan, K.S. Siddiqi and K.A. Alamry, J. Ind. Eng. Chem., 19, 595 (2013); https://doi.org/10.1016/j.jiec.2012.09.025

23. R.M. Hassan, S.M. Ibrahim, I.A. Zaafarany, A. Fawzy and H.D. Takagi, J. Mol. Catal. A Chem., 344, 93 (2011); https://doi.org/10.1016/j.molcata.2011.05.006.

24. K. Sharanabasamma, M.A. Angadi, M.S. Salunke and S.M. Tuwar, Ind. Eng. Chem. Res., 48, 10381 (2009); https://doi.org/10.1021/ie901049p.

25. J.M. Pushparaj, S. Kannan, L. Vikram, L.S. Kumar and K.S. Rangappa, J. Phys. Org. Chem., 18, 1042 (2005); https://doi.org/10.1002/poc.968.

26. K. Sharma and R.N. Mehrotra, Polyhedron, 27, 3425 (2008); https://doi.org/10.1016/j.poly.2008.08.002.

27. B. García, R. Ruiz and J.M. Leal, J. Phys. Chem. A, 112, 4921 (2008); https://doi.org/10.1021/jp800208s.

28. T.P. Jose, M.A. Angadi, M.S. Salunke and S.M. Tuwar, J. Mol. Struct., 892, 121 (2008); https://doi.org/10.1016/j.molstruc.2008.05.006

29. P.J. Babu, P. Sharma, B.B. Borthakur, R.K. Das, P. Nahar and U. Bora, Int. J. Green Nanotech.: Phy. and Chem., 2, 62 (2010); https://doi.org/10.1080/19430876.2010.532443.

30. A. Rafey, K.B.L. Shrivastavaa, S.A. Iqbal and Z. Khan, J. Colloid Interface Sci., 354, 190 (2011); https://doi.org/10.1016/j.jcis.2010.10.046.

31. D.W. Kim, S.I. Shin, S.G. Ohin, K.L. Mittal and D.O. Shah, Surface Science Series, Marcel Dekker, New York, vol. 109, p. 255 (2003)

32. A.I. Vogel, Text Book of Practical Organic Chemistry, 5th ed., ELBS \& Longman, London, edn 5 p. 1332 (1989). 